\title{
(e) Instrumento
}

ISSN 1984-5499

Licenciado sob uma Licença Creative Commons

\section{Percepção do conceito "professor" por alguns professores da 6ạ classe de ensino primário da escola Mpunzi Nzau, Cabinda, Angola}

\author{
Perception of the concept "teacher" by some teachers from the 6th grade of primary \\ education at Mpunzi Nzau school, Cabinda, Angola
}

\begin{abstract}
Percepción del concepto de "maestro" por algunos maestros del sexto grado de educación primaria en la escuela Mpunzi Nzau, Cabinda, Angola
\end{abstract}

Domingos Sebastião Luemba Sambo ${ }^{1}$

Professor do Instituto Superior de Ciências da Educação, Cabinda/Angola

Ressamo Rosa Mavungo ${ }^{2}$

Professora da Escola de Ensino Primário Mpunzi Nzau, Cabinda/Angola

Recebido em: 01/04/2020

Aceito em: 06/10/2020 10.34019/1984-5499.2021.v23.30108

\section{Resumo}

O tema é fruto de comportamento inadequado de certos professores que atuam na 6 a classe, na escola do ensino primário "Mpunzi Nzau", em Cabinda, Angola. Por vezes, tratam os seus alunos de "burros", os ofendem e dificilmente aceitam espaço de discussão da matéria. Nessa senda, desenvolveu-se esta pesquisa cujo objetivo geral foi de perceber o sentido que atribuem ao conceito de professor. Objetivos específicos, de fazer abordagem teórico-metodológica sobre professor e, compreender, através de entrevistas, como alguns professores da 6a classe da escola em causa entendem o conceito professor. Usaram-se os métodos observação, indução, bibliográfico, descritivo e a entrevista. Os principais resultados mostram que há reclamações de alunos diante de condutas de alguns professores durante as aulas. E entre os professores, também há quem reclame no modo de agir de outros colegas. A pesquisa concluiu que os professores têm domínio do conceito professor, mas poucos colocam em prática o que aprendem durante a formação, para o exercício da profissão docente.

Palavras-chave: Percepção. Conceito. Professor.

\begin{abstract}
${ }^{1}$ E-mail: domingos.sambo@hotmail.com

2 E-mail: ressamorosa@hotmail.com
\end{abstract}

The theme is the result of inappropriate behavior of certain teachers who work in the 6th grade, at the primary school "Mpunzi Nzau" in Cabinda, Angola. Sometimes they treat their students with donkeys, offend them and hardly accept space for discussing the matter. Along this path, this research was developed, whose general objective was to understand the meaning attributed to the concept of teacher. Specific objectives, to make a theoretical-methodological approach to the teacher and to understand, through interviews, how some teachers from the 6th grade of the school in question understand the concept of teacher. Observation, induction, bibliographic, descriptive and interview methods were used. The main results show that there are complaints from students regarding the conduct of some teachers during classes. And among teachers, there are also those who 
complain about other colleagues' behavior. The research concluded that, teachers have mastery of the teacher concept, but few put into practice what they learn during training, for the exercise of the teaching profession.

Keywords: Perception. Concept. Teacher.

\section{Resumen}

El tema es el resultado del comportamiento inapropiado de ciertos maestros que trabajan en el sexto grado, en la escuela primaria "Mpunzi Nzau" en Cabinda, Angola. A veces tratan a sus estudiantes con burros, los ofenden y apenas aceptan espacio para discutir el asunto. A lo largo de este camino, se desarrolló esta investigación, cuyo objetivo general era comprender el significado atribuido al concepto de maestro. Objetivos específicos, hacer un acercamiento teórico-metodológico al maestro y comprender, a través de entrevistas, cómo algunos maestros del sexto grado de la escuela en cuestión entienden el concepto de maestro. Se utilizaron métodos de observación, inducción, bibliográficos, descriptivos y de entrevista. Los principales resultados muestran que hay quejas de los estudiantes con respecto a la conducta de algunos maestros durante las clases. Y entre los maestros, también hay quienes se quejan del comportamiento de otros colegas. La investigación concluyó que los maestros dominan el concepto del maestro, pero pocos ponen en práctica lo que aprenden durante la capacitación, para el ejercicio de la profesión docente.

Palabras clave: Percepción. Concepto. Maestro.

\section{Introdução}

O conceito "percepção" (CABRAL; NICK, 2007) está vinculado ao professor, sendo ele indivíduo que ensina e deve trabalhar com zelo em atividades nas quais se inclinou ou se inclina. Pressupõe-se com isto que, ao longo da sua formação, foi-se munindo de ferramentas para o exercício da sua profissão.

Essa ferramenta se adquire no processo de ensino e aprendizagem em instituições próprias que atribuem o título ao professor. E essa informação pode ser consultada entre outras fontes, nos Estatutos do Subsistema de Formação de Professores (ANGOLA, 2001, 2016; RAMOS, 2019, p. 30-34). Os documentos defendem que o professor que exerce atividade professoral até o 1 o ciclo do ensino secundário é um técnico, formado em Magistérios Primários e em Escolas de Formação de nível secundário, que os habilita para o exercício docente. A isso se entende que há todo um conjunto de dispositivos teórico-práticos a serem munidos, que habilita a pessoa para o exercício da profissão docente, de acordo com seu nível de atuação.

Nos termos do artigo 260 da Lei de Base do Sistema de Educação em Angola (ANGOLA, 2001, p. 9-11), o subsistema de formação de professores consiste em formar docentes para a educação préescolar e para o ensino geral, nomeadamente a educação regular, a educação de adultos e a educação especial.

Em outras palavras, entendemos com isso que, dentro desse processo, o formado aprenda o essencial para assegurar a vida profissional, como por exemplo, a forma como comportar-se na sala de aulas perante os seus alunos, a motivação para o sucesso acadêmico, entre outros aspectos que 
conformam a sua profissão.

Enquanto professores, é muito comum constatar-se em várias escolas do ensino primário professores que carregam consigo comportamentos que, ao nosso entender, são reprováveis para a profissão que exercem. Pois demonstram, pelo que nos parece, pouco amor à profissão e dão pouco espaço de fala aos alunos. Esses sofrem represálias por parte dos que ensinam, por vezes, com palavras grosseiras, que nada sabem, ameaças às reprovações. Alguns professores ainda navegam no conceito de tábua rasa (FREIRE, 1992) e resistem em apreender as opiniões dos alunos. Por conseguinte, desprezamnos. Entende-se que essa realidade não se adequa ao processo de ensino e aprendizagem, pelo fato de o conceito de tábua rasa ter um sentido pejorativo, ao nosso entender. Pois, traz a ideia de que o aluno nada sabe e o professor é o único detentor de saberes. O saber está centralizado no professor e cabe ao aluno escutar, apreender e reproduzir o que vem dele, apenas.

Ao contrário disso, entende-se que o professor deve perceber o aluno como seu centro das atenções e, como tal, deve ser mediador, facilitador e orientador; alguém que ajuda o aluno a perceber e acatar os conteúdos no processo docente educativo. O professor é aquela pessoa que encontra a satisfação na realização da sua atividade docente e ensina com estima, considerando os seus alunos como seus próprios filhos. Tudo faz para ajudá-los a superar os seus obstáculos. Por um lado, e por outro, deve ser ainda aquele indivíduo que se preocupa mais com os seus alunos, com seu trabalho do que consigo mesmo. Infelizmente, não é o que se tem vindo a constatar em alguns da escola do ensino primário Mpunzi Nzau (Cabinda, Angola).

Isso impeliu-nos a buscar alguns trabalhos de fórum acadêmico-científico de produção local sobre o que os professores entendem do conceito professor. Não foi localizado nenhum trabalho a respeito, na realidade local. Mas, entende-se que: todo o professor deve munir-se de comportamento apropriado na sala de aula enquanto alguém que ensina. Deve amar, orientar, aconselhar, considerar seus alunos etc. e tê-los como oportunidade da sua autoavaliação relativa à sua posição enquanto professor.

Pela experiência enquanto professores, essas atitudes constituem condição necessária que o professor deva munir. Parece-nos ainda estar longe em alguns deles à luz daquilo que se tem vindo a observar no processo docente educativo. É diante dessa realidade exposta que se desenvolveu esta pesquisa, cujo objetivo geral foi de perceber o sentido que atribuem o conceito professor e objetivos específicos de fazer abordagem teórico-metodológica e compreender por meio de entrevistas como alguns professores da 6ạ classe da escola do Ensino Primário Mpunzi Nzau, em Cabinda, Angola, entendem o conceito professor. No entanto, vale realçar que a 6a classe que aqui se refere faz parte do 
ciclo básico e é a última classe desse ciclo de ensino primário (cf. entre outras fontes RAMOS, 2019, p. 24-28).

\section{Metodologia}

Do ponto de vista metodológico, caracterizou-se a escola, local de pesquisa. É uma instituição do ensino público onde estudam alunos do ensino primário, localizada em um dos bairros suburbanos de Cabinda, chamado Mpunzi Nzau, nome herdado pela mesma escola.

A escolha dessa instituição de ensino se deu pelo fato de aí ouvir-se, por intermédio de alguns professores que lá trabalham, reclamações sobre o modo de atuação de alguns colegas ao longo do exercício de atividade docente. Afirmam que alguns ofendem moralmente seus alunos, desrespeitam as suas opiniões, os consideram que nada "ou quase nada" sabem e muitas vezes são impostos a consumirem aquilo que apenas vem do professor. E isso, em pleno século XXI, já não deve constituir modus operandi de um professor, pelos conhecimentos que carregamos, e nem considerar seus alunos como tábua rasa. Essa realidade, em diálogo ao interesse de pesquisar a atuação dos professores no ensino básico na sala de aula, ajudou a definir esta pesquisa para buscar deles a compreensão que têm do conceito professor.

O corpo docente da instituição em causa é heterogêneo quanto à formação e alguns deles com vasta experiência docente (mais de 9 anos). Uns trabalham no sistema denominado módulo e outros no critério normal. O sistema de módulo é um programa de alfabetização e aceleração escolar, reservado, preferencialmente, para alunos com atraso de nível de escolaridade. Em um total de três módulos, cada um deles representa um intervalo de classe correspondente, sendo, para o módulo 2, aqueles alunos com noções de leitura e escrita (equivale a 3ạ e 4ạ classes); já o módulo 3, reservado aos alunos com conhecimentos mais consistentes em relação ao módulo anterior, "equivale à 5ạ e 6ㅁ classes" (FUMBA, 2013).

Para tal, identificou-se no seio de coletivo alguns professores com condutas consideradas inadequadas na profissão que exercem. Foi possível essa constatação a partir da observação das suas condutas durante as aulas e fora de aulas, no espaço escolar.

Do universo de professores, sete (7) identificados com a conduta referida e quatro (4) se disponibilizaram de forma livre a participar da pesquisa, depois de terem sido contatados e convidados para o efeito. Quer dizer, a sua livre participação foi tida como mecanismo da sua seleção. São todos de 
idade adulta, dos 37 aos 42 anos, com o tempo mínimo de 10 anos de experiências. Três deles em fase da conclusão do curso de licenciatura (graduação) vinculado ao ensino e um deles em formação média em uma das instituições sem vínculo educacional (ou não vinculado à formação de professores). Ou seja, dos quatro professores que fizeram parte da pesquisa, três deles estavam matriculados e se encontravam na fase de conclusão da sua graduação em uma instituição do Ensino Superior com o vínculo pedagógico (formação de professores). E o outro, a estudar em uma das escolas do Ensino Médio, mas não vinculado à formação de professores.

Optou-se por entrevista como instrumento e técnica de coleta de dados, porém, para a sua aplicação, se fez uma espécie de preparação psicológica dos entrevistados, antes da entrevista, de modo que eles pudessem se sentir seguros e à vontade. Explicou-se a que se devia, para que fins, que significado tinha a pesquisa e se garantiu o anonimato. Assim sendo, solicitou-se a disponibilidade de cada um no sentido de se manifestar quando estaria disponível para a entrevista, mas de forma isolada, sem a presença de outra pessoa que não fizesse parte da pesquisa.

De acordo com a disponibilidade de cada um deles, as entrevistas foram de forma separada, gravadas, transcritas e analisadas no critério categorial (GOMES, 2012). Isto é, depois de transcritos os conteúdos, foram avaliados e reconstruídos em categorias de análise. Ou seja, agruparam-se as respostas semelhantes vindas de cada um dos sujeitos de pesquisa e congregados em categorias: idade e tempo de experiência profissional, área de formação, instituição e classe, conceito professor (ser professor), características gerais que deve possuir um professor, características específicas dos professores da escola Mpunzi Nzau, e este último com as respectivas subcategorias de análise, respectivamente: comportamentos dos professores da escola Mpunzi Nzau; conduta imoral desses que ensinam na escola Mpunzi Nzau; conselho para os colegas professores; e que os professores da escola Mpunzi Nzau ouvem de seus alunos e a visão sobre os docentes da instituição.

No entanto, para garantir o anonimato de sujeitos de pesquisa, foram atribuídos nomes fictícios, isto é, falsa identidade, e nenhum de tais nomes representa pessoa física de algum dos seus funcionários, pelo menos até a altura da pesquisa (em Angola, pelo conhecimento que carregamos, a comissão nacional da ética ainda não funciona). Recorreu-se a métodos de observação, indução, abordagem qualitativa, pesquisa bibliográfica e descritiva e a técnica de entrevista.

Quanto à localização da escola, ela se encontra situada em uma das zonas suburbanas, denominada Mpunzi Nzau, na cidade de Cabinda. Dista cerca de $6 \mathrm{~km}$ do centro da cidade e a 1,5 km do aeroporto local em direção Sul, tendo como referência a estrada nacional que dá acesso à fronteira do 
Yema, República Democrático do Congo (RDC). Com aquele país, Cabinda faz fronteira ao Sul e ao Leste, e ao Oeste, pelo oceano atlântico.

A escola tem uma estrutura organizacional e administrativa própria, que lhe permite matricular alunos da primeira à sexta classes, correspondendo ao primeiro ciclo do ensino básico (1aa , 2aa , 3aㅡ, 4aㅡ, 5aㅡ e 6a classes) que nela funcionam. É nessa última classe onde se registram alguns professores que apresentam condutas de desrespeito, ofensas, que tratam alunos de "burros" e com alguns desses professores se desenvolveu esta pesquisa.

\section{Conceito de percepção}

A percepção é um processo no qual o indivíduo tem consciência dos objetos e meios que o rodeiam, podendo se desdobrar em sensorial e social, no seio de outras (CABRAL; NICK, 2007). De acordo com a fonte assumida, a sensorial é: “o conjunto de fenômenos e processos pelos quais, percebemos, descriminamos e retratamos o mundo dos objetos e eventos físicos, que servem de estímulo, através dos sentidos orgânicos ao nosso comportamento psicofísico" (CABRAL; NICK, 2007, p. 223).

E a percepção social não é nada mais senão aquela forma de perceber os objetos sociais, quer se trate de pessoas quer de grupos sociais. Reforça a fonte que se trata da percepção dos comportamentos da pessoa em relação às suas atitudes, sentimentos ou intenções, sendo essa a percepção que se propôs trazer à tona de alguns professores da escola do ensino primário Mpunzi Nzau/Cabinda, Angola, na sua dimensão profissional.

Em outras palavras, refere ao que alguns professores daquele estabelecimento de ensino percebem do próprio termo professor, enquanto protagonistas da opinião, no olhar pedagógico. Um olhar que diz respeito ao educador em várias dimensões de seu trabalho, na condução de crianças no processo docente educativo, ou seja, o ensino e aprendizagem. É esse olhar que se quer aqui perceber dos sujeitos de pesquisa que são alguns professores da escola referida.

\section{Professor e suas dimensões como espelho da sociedade}

O professor é um espelho da sociedade que, em diálogo com Libâneo (1994), tem uma responsabilidade social enorme e que se compromete na luta pela transformação social. É aquela pessoa que na sala de aulas exerça uma função política que não deva passar de forma despercebida pelos alunos (FREIRE, 1996). Ele deve deixar explícita a sua competência em analisar, decidir, optar, comparar, avaliar 
e procurar despertar, também no aluno essa consciência política. Requer no sentido geral uma pessoa dotada de competências quer na sua natureza humana, quer nos seus saberes específicos ligados à docência, conforme afirma Freire (1996).

O professor ainda é aquela pessoa munida de competências sociais e morais, aceitáveis na sociedade pelo respeito, atenção e consideração da pessoa humana, munido de vários saberes como, por exemplo, aqueles de Delors (1998). São saberes que constituem pilares da educação e enquanto professor deve se rever neles: saber viver, saber ser, saber fazer e saber aprender. Nesse caso, são elementos que devem revestir um determinado profissional, pois ser professor requer qualidades ou requisitos indispensáveis no exercício da profissão, como por exemplo, aquelas ligadas aos conhecimentos básicos na prática de ensino e refletivo (ARENDS, 2008). São esses, no nosso entender, que sustentam a vida profissional na docência.

Candau et al. (1995) revejam-se no conjunto desse manancial para reafirmar que esses aspectos não fazem parte só do processo de ensino e aprendizagem, mas também da vida dos seres humanos, devem ser entendidas em três dimensões: humana, político-social e técnica.

\section{a) Dimensão humana}

A dimensão humana da formação didática/pedagógica é caracterizada pela compreensão dos valores éticos, das crenças religiosas, da afetividade, da emocionalidade, da racionalidade. Numa perspectiva dialética, o homem é compreendido como um ser complexo que se constitui como síntese de múltiplas determinações, como um conjunto de relações sociais. Ele é concebido como um ser "inacabado", que participa continuamente de um processo dinâmico de construção do mundo e de si mesmo. Nesse sentido, o aluno é entendido como um ser social integrado, com períodos de desenvolvimento cognitivo, afetivo, social e motor, isso é, como uma pessoa em suas múltiplas dimensionalidades (CANDAU et al., 1995).

Esta dimensão (dimensão humana), de uma forma ampla, refere-se ao relacionamento interpessoal que ocorre no processo ensino e aprendizagem entre os sujeitos envolvidos, no que toca a aspectos fundamentais como: a forma como o professor se relaciona com seus alunos; a forma como ele enfrenta a docência; os cuidados que ele dispensa àquele aluno que possui um grau maior de dificuldades e ao próprio ambiente que é criado na sala - de respeito, de amizade, de apoio, de incentivo, de sonhos e conquistas - pelo qual o principal responsável é o professor (CANDAU et al., 1995). 


\section{b) Dimensão político-social}

Essa dimensão reveja-se, na perspectiva de Vasconcelos (1999), como sendo aquela em que quer o professor, quer o aluno, ambos se identificam com a sua história da vida, o que de certo modo, se pressupõe de hábitos culturais, ou seja, de cultura específica. Daí, os saberes estarem atrelados a realidades sociais de ambas as partes (professores e alunos) articulando-os às necessidades concretas de vida desses alunos. Nessa senda, a prática no exercício da profissão deve dialogar com o período da história que distingue a sociedade. Por isso, a metodologia a usar deva identificar-se para essa finalidade.

\section{c) Dimensão técnica}

A dimensão técnica se reveja no domínio de conteúdos que são desenvolvidos durante o ensino e a capacidade de fazer viver na vida dos alunos as matérias que são lecionadas pelo professor (CANDAU, 1996). De acordo com a autora, isso se caracteriza de forma intencional, orientados por intermédio de metas a atingir, recorrendo a conteúdos previamente selecionados, claro, com apoio de técnicas, recursos de ensino, organização de processo de avaliação e escolha, planificação de aulas, entre outros.

\section{Diálogo das dimensões humana, político-social e técnica com a realidade angolana}

No contexto dessas dimensões (humana, político-social e técnica), "durante a formação" ensinase que, na dimensão humana, o professor deve revelar-se de um perfil digno que reflita a sua personalidade e responsabilidade, no sentido positivo; proceder-se sempre como um modelo que atrai os alunos e não só ele deve estar dotado de capacidades cognitivas para realizar o seu trabalho, ser compreensível, saber respeitar o lado humano, evitar atos que podem manchar a boa convivência com o seu semelhante.

$\mathrm{Na}$ categoria político-social, ele deve ser um filósofo e político, no sentido de intervir nas ocorrências da comunidade, estar sempre a par e passos de tudo que aí acontece e participar nas soluções dos problemas que afetam a sociedade. Mostrar aos seus alunos a importância de saber o que se passa no país e no mundo, ajudá-los a se tornarem bons cidadãos e amantes da pátria, cumpridores dos seus deveres cívicos como: fazer o registro eleitoral, votar, no caso dos que se encontram em idade para isso, saber respeitar o bem público e as instituições públicas. Antes que ele ajude os seus alunos a fazê-lo, deve ser o primeiro a cumprir, ensinar com exemplos práticos é sempre a melhor forma.

Finalmente, na categoria técnica, o professor deve saber aplicar na prática todo o conjunto de 
teorias aprendidas ao longo da sua formação. Deve ser capaz de aplicar diversas metodologias de acordo com a situação da aula, pois é na aplicação dos métodos e técnicas na sala de aula que os professores se distinguem entre eles. A capacidade técnica de um professor se verifica quando este for capaz de utilizar um conjunto de métodos para conseguir resolver as situações que ele encontra durante a realização da sua atividade laboral.

Portanto, o "instrutor" que é capaz de desenvolver as suas habilidades na categoria humana, político-social e técnica, é um professor exemplar e digno de se tornar um modelo para os seus alunos, os colegas da profissão e a sociedade em geral. Por isso, durante a sua formação, os professores aprendem a pedagogia, didática geral, psicologia, sociologia, filosofia etc., bem como as metodologias e didáticas específicas. Eles são chamados a materializar todo esse conhecimento na prática docente.

Porém, apesar disso, pressupõe-se ainda que há muito por se fazer no sentido de melhorar os aspectos negativos que enfermam o professor angolano e o processo de ensino, uma realidade discutida por Peterson (2003). Ele fez reflexão sobre a formação de professores angolanos, apontando-nos grandes problemas que devem necessariamente ser resolvidos, que afetam o ensino de base, sendo: o professor não consegue atingir níveis satisfatórios no ensino, a má preparação acadêmica de base, a falta ou o pouco conhecimento pedagógico, turmas excessivamente grandes e a instabilidade social. São elementos a ter em diálogo com as qualidades do nosso professor angolano. Aponta de igual modo a heterogeneidade deste profissional muitos dos quais, no passado, exerciam suas funções sem prévia formação correspondente, o que, de certo modo, afetou grandemente o processo de ensino e aprendizagem do país. No entanto, hoje, requer outra postura, nova dinâmica, aceitação do novo para melhorar o velho. Isso dialoga com a reflexão de Sambo (2018) quando se referia à necessidade de mudança radical daquilo que afeta Angola, na sua obra intitulada "Precisamos sair dessa!".

$\mathrm{Na}$ senda disso tudo, o estilo do processo de ensino e aprendizagem, o modo de gestão e a preparação obtida ao longo da sua formação, assim como o comportamento e atitude do professor, no contexto de Angola, dependem de inúmeros fatores, econômicos, políticos, científicos e culturais (PETERSON, 2003). São eles que determinam as qualidades que o nosso professor deve necessariamente possuir: capacidade de conhecimento e atitude, capacidade profissional, capacidade de gestão de ensino e a capacidade de atitude social.

É nesse olhar que o autor Peterson (2003, p. 103-110) define o professor como sendo: "combatente da linha da frente"; "promotor da criação do homem novo"; "ativista da transformação das relações sociais"; "quadro político e dinamizador das iniciativas da comunidade"; "renovador do sistema 
educativo (educador, guia, mediador, avaliador, agente do desenvolvimento)"; "animador social e modificador de atitudes e representante do estado".

\section{Tipologia de professor e a realidade em Angola}

Falar desse item é mostrar inicialmente como se dá a formação do professor em Angola para atuar nos diferentes níveis da educação básica e não só. Nisso, existe uma estrutura organizacional própria do sistema educativo angolano que regula o seu funcionamento, a lei n. 17/16 de 7 de outubro. Essa lei mostra como o processo de formação deve acontecer. Todas as outras políticas públicas e de programas nacionais devem se rever dessa lei, quer seja pela estrutura organizacional e funcional do sistema de educativo e ensino (RAMOS, 2019).

Observam-se, nessa lei, os vários subsistemas que comportam a educação e o ensino na República de Angola, a saber: "pré-escolar, ensino geral, técnico-profissional, formação de professores, educação de adultos e do ensino superior" (RAMOS, 2019, p. 19-38). Todavia, fazemos ênfase ao subsistema da educação de adultos no qual esses professores atuam. Mas, para atuar em qualquer dos subsistemas, tem de ter uma formação sólida suportada de conhecimentos técnico-científico, consciência patriótica e democrática a favor das novas gerações (RAMOS, 2019, p. 30). E essa formação se dá após a nona classe, mas em instituições específicas, vocacionadas para formação de professores. Nessa senda, o tipo de professor em muito tem a ver com a instituição formadora, a consciencialização dos conteúdos recebidos durante a formação e como interage na prática os conhecimentos adquiridos para o exercício da profissão docente.

Falar do tipo de professor é assunto que se entende ser complexo pelas várias concepções a respeito. Nesse sentido, Formosinho (2009) realça que na análise do desenvolvimento profissional dos professores, contrapõem-se dois tipos de professores, o professor artesão e o professor perito.

Na visão do autor, o primeiro tipo referido não faz esforço para acompanhar o dinamismo da ciência. Ele é limitado nos conhecimentos adquiridos há muito tempo. Diz ser experiente nisto ou naquilo, não é capaz de causar mudanças inovadoras nos seus alunos, tornando-os estáticos porque ele também é estático. Suas características, de acordo com a fonte, se revejam em: serem experientes e possuidores de conhecimentos vindos da sua cabeça e do seu coração; a base de tais conhecimentos é única; fazem reprodução de planos de aula há décadas e têm resistência para mudança. Para esses professores, o material que apresentam é uma fonte rica de informações que transformou as suas vidas 
convencendo-os do poder do conhecimento artesanal por meio da prática.

Na verdade, no contexto angolano, é muito comum observar-se esse comportamento, em certos professores. Diante dessa conduta, há muita dificuldade entre alunos, basicamente, naqueles que acompanham a evolução da ciência e da técnica. E as discussões em relação ao processo estático do professor tem merecido desavenças entre a preservação do passado e a resistência na mudança que são impostas pelo professor.

O considerado perito é aquele professor que reúne as capacidades de interpretar na prática os conhecimentos que adquiriu na sua formação e admite novas visões à luz da ciência. Assim sendo, ele, perito, é considerado um potencial núcleo de informações, de conhecimentos, de competências que ele reúne, graças à aceitação do velho ao novo. Investiga, critica, se reveja no espírito de humildade científica, aceita conselhos para o seu crescimento. Aceita e participa de cursos de superação, palestras, seminários, jornadas etc. (FORMOSINHO, 2009). Também no contexto angolano, é notório esse tipo de professores.

Diante da explanação até aqui assumida, entende-se que ser professor não é uma tarefa fácil, requer aspectos "sui generis" que podemos chamar de requisitos.

\section{Requisitos para ser professor}

Para que um educador se torne professor que se almeja, deve estar alinhado a alguns pressupostos que dialogam com a formação didática-pedagógica. De acordo com Formosinho (2009), o professor deve necessariamente munir-se de capacidades de ensinar conteúdos por intermédio de interação entre os sujeitos envolvidos na matéria. Com isso, é importante que o professor tenha competências de o fazer, mas elas são adquiridas por meio de formação que instrumenta a pessoa a transmitir metodologicamente o que ele ensina. Importa realçar que as qualidades pessoais, a capacidade retórica, ligadas à prática de ensino, à reflexão e ao espírito criativo, são potenciais aspectos que caracterizam os requisitos ao professorado.

Relativamente às qualidades da pessoa humana, ou seja, qualidades pessoais, reter aqui que as relações interpessoais são necessárias, quer em salas de aulas, quer fora delas. O entrosamento entre as pessoas, a manifestação do afeto, a capacidade comunicativa, o respeito mútuo são de extrema importância.

Revela Mena (2016) que a capacidade do professor em preparar as suas aulas e ter o domínio do 
conteúdo a administrar, mas em atenção que esses conteúdos devem conciliar com a idade cronológica e inteletual em consonância aos objetivos, são também requisitos ao longo do exercício da profissão. E a capacidade retórica em ligação à reflexão que é feita nos conteúdos devam conduzir à resolução de problemas, conforme Formosinho (2009 apud Mena, 2016). E o professor deve, sim, se rever nesses requisitos.

Em suma, para ser professor, não basta ter formação correspondente, mas, sim, aliado à vocação, ao carinho, ao gosto do que faz, ao afeto e à humildade. Só assim poderá respeitar seus aprendizes e têlos como companheiros ao longo do exercício da profissão.

Face ao anterior, afinal, o que o trabalho de campo nos revela?

\section{Apresentação, análise e interpretação dos resultados da entrevista}

Tal como referido antes, a entrevista foi feita e, em função dos objetivos traçados e da própria metodologia, permitiu construir categorias vindas de respostas de cada um dos entrevistados. Ao ser asssim, a primeira categoria mostra a idade e o tempo da experiência profissional, conforme a Tabela 1.

Tabela 1

Idade e tempo na profissão

\begin{tabular}{l|l}
\hline \multicolumn{1}{c|}{ Idade } & \multicolumn{1}{c}{ Tempo na profissão } \\
\hline 37 anos & 13 anos \\
\hline 39 anos & 18 anos \\
\hline 40 anos & 20 anos \\
\hline 42 anos & 10 anos \\
\hline
\end{tabular}

Fonte: Pesquisa de campo própria.

Podemos entender que os quatro sujeitos de pesquisa são todos professores com idade adulta que vai desde os 37 aos 42 anos de idade, e uma experiência profissional que vai dos 10 aos 20 anos. Essa experiência profissional revela, na prática, conhecimentos acumulados a respeito dos conteúdos que lecionam, como também o posicionamento de cada um na sala de aulas, no que toca a sua conduta.

No entanto, tendo em consideração que esses professores supostamente apresentam postura inadequada, desrespeitam os seus alunos, desprezam as suas ideias, os colocam na condição de consumidores passivos, não os deixam reagir diante de conteúdos vindos do professor, como se os 
alunos nada soubessem, houve necessidade de procurar saber dos sujeitos de pesquisa a área de formação e a instituição formadora de modo a explorar seus conhecimentos no contexto profissional, conforme a categoria correspondente: área de formação, instituição e classe (Tabela 2).

\section{Tabela 2}

Área de formação e instituição formadora

\begin{tabular}{l|l|l}
\hline Área de formação & Instituição formadora & Total \\
\hline Pedagogia (ensino primário) & $\begin{array}{l}\text { Instituto superior de ciencias da educação } \\
\text { (ISCED) }\end{array}$ & 1 \\
\hline $\begin{array}{l}\text { Pedagogia (Gestão e Inspeção } \\
\text { Escolar) }\end{array}$ & $\begin{array}{l}\text { Instituto superior de ciencias da educação } \\
\text { (ISCED) }\end{array}$ & 1 \\
\hline Biologia & $\begin{array}{l}\text { Instituto superior de ciencias da educação } \\
\text { (ISCED) }\end{array}$ & 1 \\
\hline Ciências Físicas e Biológicas & Pré-universitária & 1 \\
\hline Total & 2 & 4 \\
\hline
\end{tabular}

Fonte: Pesquisa de campo própria.

Conforme a tabela, os sujeitos de pesquisa são estudantes, até a altura da pesquisa, pertencentes a duas instituições de ensino, uma de nível superior (graduação) vocacionada ao ensino e outra do nível médio, não voltada ao ensino, ou seja, não voltada à formação de professor. Todos eles atuam na sexta classe.

Entende-se que a formação do professor é uma variável de extrema importância que consiste em instrumentar o beneficiário para o exercício da sua atividade. Nesse contexto, Cabinda beneficia de instituições vocacionadas para o efeito (Instituto Superior de Ciências da Educação-ISCED, Escola de Formação de Professores-EPF e Ajuda para o Desenvolvimento do Povo para o Povo-ADPP, em Cacongo). $E$, no seio desses professores pesquisados, existe aquele que não tem formação em educação, portanto, não habilitado tecnicamente em dar aulas e se encontra no processo de formação em uma instituição pré-universitária (PUNIV).

De acordo com Peterson (2003), algumas preocupações que afetam o ensino de base estão ligadas em não conseguir atingir níveis satisfatórios no ensino por causa de algumas pessoas que exercem a atividade docente não ostentarem de formação pedagógica requerida para o exercício da profissão. Para o exercício da atividade professoral, é fundamental que, durante a formação, o formando se instrumente de ferramentas que lhe potenciam, entre elas, por exemplo, as pedagogias, as didáticas e as psicologias. A falta desses elementos pode afetar o professor porque se deparará com dificuldades de posicionar-se em todos os sentidos como professor. 
No contexto geral, começa a se explorar o que é afinal ser professor. Os sujeitos de pesquisa revelam quem é professor na base categoria "conceito professor (ser professor)".

Ser professor é [...] alguém que é formado na área de pedagogia, que assume a sua responsabilidade como professor na sala de aulas. (Joana)

Ser professor é ser um guia de transmitir os conhecimentos aos alunos. (Suzana)

[...] é ser um guia, alguém que conduz o homem igual para amanhã ser alguém. (Antônia)

[...] ser professor é sempre ser exemplar, condutor, dirigente, formador do futuro do amanhã. (Emiliano)

Sabe-se que o conceito revelado aqui corresponde àquilo que, na verdade, o sujeito deve ser. Um sujeito que, em princípio, deve ter conhecimentos de pedagogia, didática, assim como outros conhecimentos como da psicologia para melhor transmitir os conteúdos e conduzir seus alunos. Na base disso, a outra questão explorada foi o de saber das características do professor, conforme a categoria correspondente.

Na minha opinião um professor deve ter boas características, como por exemplo, a boa forma de se dirigir com os alunos, boa forma de se dirigir com os colegas e perante a sociedade e assumir os seus alunos na sala de aulas. (Joana)

Na minha opinião, o professor deve possuir boas características, e deve ser exemplar. 0 professor tem de ter boas maneiras, deve ser exemplar; vestir bem. (Suzana)

Em primeiro, o professor deve ser dedicado na profissão que faz, deve ter amor na profissão que faz, e acima de tudo, muita responsabilidade. (Antônia)

Um professor deve possuir as seguintes características: ser compreensível, amar a todos, e duma forma de igualdade, pacífico. (Emiliano)

Para o coletivo, todo professor deve possuir determinadas características que são: competências de dirigir os seus alunos e saber relacionar-se com os colegas; ser bem apresentado e manter sempre boa imagem; ser dedicado, ter amor e responsabilidade ao trabalho; finalmente, ser compreensível com os alunos e colegas e ser justo diante de todos, tal como constatamos ao longo da revisão da literatura.

A categoria em análise trouxe subcategorias que frisam o específico dos professores da escola em referência: comportamentos de professores da escola, conduta imoral, conselhos para outros colegas da escola, entre outros.

Diante do comportamento, apontam que:

[...] há professores que maltratam os alunos, não falam bem, e os alunos aí são obrigados, às vezes fugir, ter medo do professor; às vezes não tem como se dirigir com o professor por causa do comportamento de certos colegas. (Joana)

[...] temos visto professores a maltratar mesmo os alunos, (...) até outros ofendem mesmo, olha cara dele! Olha bem feio! Olha vista dele; (...) tem mesmo aqueles 
professores que maltratam os alunos. Quando é para bater, é bater mesmo (...) 5, 6, 7, vezes. É muito para uma criança. É contra a pedagogia maltratar a criança. (Suzana)

Aqui na escola nós temos um comportamento amigável, um comportamento de delicadeza, um comportamento de irmandade. (Antônia)

Onde há coletivo sempre há vários vícios, fofocas, há sempre coisas indiretas, mas, há colegas que se comportam mesmo bem, como um ser humano, como alguém que corresponde ao plano, ou programa, o pensamento do outro. Mas outros, há sempre aqueles conflitos que já é difícil entender na coletividade. (Emiliano)

Os relatos dos sujeitos de pesquisa apontam certos professores na instituição que apresentam comportamento inadequado, alguns apresentam vícios como fofoca, inveja e difamação; chegam ao ponto de maltratar alunos e, fruto disso, os próprios alunos reagem negativamente ao comportamento dos professores. Isso tem vindo a comprometer boas relações não só com os alunos, mas também, entre colegas. E como consequências, alguns professores não se falam, e outros começam com a perseguição e, por vezes, geram conflitos que estendem até em suas casas.

No contexto dessa situação, os alunos receiam de participar das aulas, não apresentam dúvidas e apresentam-se tímidos. Ao acontecer, torna-se perigo para a sua aprendizagem, pois mesmo tendo uma necessidade, não conseguirá dizer por causa da timidez imposta pela presença do professor. Daí que as boas relações interpessoais com alunos, colegas, pais, direção das escolas devam ser aplausíveis para não afetar de forma negativa o trabalho docente-educativo.

Quanto à conduta imoral, como uma das subcategorias identificadas, é preciso acima de tudo, compreender que cada sociedade tem normas que regulam seu meio social. E os próprios professores enquanto parte integrante dessa sociedade fazem observações típicas na forma de vestir. Ou seja, a mulher africana, em particular cabindense, tem um vestir característico da sua identidade cultural que se traduz na sua beleza. Exemplo, uso de panos, de blusas que cobrem o tronco, de saias abaixo de joelhos... Essa prática está perdendo espaço, achamos que é por causa da influência de outras culturas, salvo algumas senhoras que ainda se apresentam de tal forma. E a reflexão que se faz disso é que as professoras, independentemente da idade, deveriam ser exemplos nesse sentido, a sua maneira de vestir, de se apresentar, deve inspirar as novas gerações. Pressupõe-se com isso que elas poderiam aproveitar a oportunidade para ensinar os jovens que "constantemente" estão a vestir fora da norma moral dos cabindas, por isso, afirmam:

Nós temos visto colegas aqui na escola que se apresentam muito mal, usam roupas que não dá para vestir e ela fica à frente das crianças, ela fica sentada e toda cueca fora, e assim não é bom professor. (Suzana) 
Aqui está! A observação feita está associada à violação de normas requeridas no contexto da sociedade angolana e aproveita esse aspecto, entendido de dissocial para tecer crítica à conduta imoral dos professores na sala de aulas. Mais do que uma observação crítica, oferece receita para o contexto angolano de como o professor deve se comportar ao longo da sua atividade laboral:

[...] no meu âmbito, não acho bem. Um professor não pode maltratar o aluno. Deve ser amigo ou mãe dos seus alunos. Quando o aluno está a se comportar mal, chama e conversa com o aluno, [...] até outros ofendem mesmo, olha cara dele! Olha bem feio! Olha vista dele. Fica muito mal para um pedagogo que aprendeu dar aulas na escola. [...] não pode maltratar um aluno. Está muito errado; é antipedagógico. Não podemos ter esse tipo de comportamento. Os nossos alunos são nossos filhos. Da forma que tratamos os nossos filhos é da mesma forma que devemos tratar os nossos alunos porque eles são nossos filhos e nós somos as segundas mães aqui na escola; não podemos maltratar os nossos alunos. (Suzana)

Diante dos conselhos dessa professora, surgiu outra preocupação em explorar o que os próprios professores ouvem dos alunos, partindo dos comportamentos considerados imorais para a cultura local. A resposta é trazida à superfície a partir da questão: em função desses comportamentos, o que é que você tem ouvido dos alunos?

Temos ouvido muita coisa dos alunos, há alunos que são mesmo abertos, falam mesmo de certos comportamentos de alguns professores, dizem que aquele professor é achado e cozido, maltrata, faz aquilo. Então temos escutado muitas lamentações por parte dos alunos. (Joana)

Os alunos falam mal, os alunos dão nomes, pior se o professor é muito pontual. Eles te dão nome. Aquela professora nunca faltou. (Suzana)

[...] alguns alunos comentam quando este professor é responsável, é pontual. (Antônio) Os alunos muitas vezes reclamam, chamam alguns professores de nomes, porque este professor é assado e cozido; quer dizer, o comportamento do próprio professor até inquieta o próprio aluno, razão pela qual há mesmo sempre reclamações entre eles: o professor fulano é assado e cozido, mas, tem sempre aquele de referência. Têm professores com este caráter, de querer sentir-se superior ao seu aluno. (Emiliano)

O professor é um educador que, na prática diária das suas atividades, deve fazer autoavaliação de si e atento aos comentários de qualquer natureza provenientes de fora e dentro da instituição sobre a sua atuação. Duas espécies de reclamações que os professores ouvem de alunos: reclamações direcionadas aos professores dado ao comportamento considerado inadequado durante as aulas e a aquela voltada aos que consideram de pontuais e assíduos, portanto que pouco faltam ao trabalho.

Relativo ao comportamento inadequado na atuação do professor, destacam-se maus tratos aos alunos, inquietação imposta aos alunos sentindo-se superiores a esses. Em linhas gerais, conduta negativa dos professores. Se por um lado se verifica essa realidade, por outro, reclamam de nomes que 
Ihes são atribuídos pelos alunos: assado, cozido... pouco faltam durante as aulas, o que revela sua responsabilidade e pontualidade.

Mas apesar de tanto que se fala de professores, por si só, eles enquanto grupo de profissionais daquela instituição de ensino primário, têm uma visão específica de como são:

Os professores do Mpunzi Nzau, eu acho que são professores mesmo unidos, têm amor ao próximo, têm a união, embora que onde está alguns indivíduos não faltam problemas, mas sabemos como resolver esses problemas. (Joana)

Eu acho do professor do Mpunzi Nzau, ... posso dizer assim ... tem bom comportamento, tem boas maneiras; ... somos amigáveis, embora todos não sejam iguais, mas tem sempre o que tem mesmo boas maneiras. (Suzana)

O professor de Mpunzi Nzau é um professor... trabalhamos sim ou trabalha, mas nem todos temos aquela responsabilidade que deveríamos ter [...]; nem todos se dedicam, talvez os outros porque querem ser professores, se sente vocacionado pela profissão que ele faz. (Antônia)

Professores de Mpunzi Nzau são conflituosos, apesar que depois do conflito tem havido algum entendimento; concernente aos nossos alunos, outros têm aquela capacidade de querer desprezar, neutralizar a bagagem que veio com o aluno, mas, contudo, sempre vão atingindo os objetivos. (Emiliano)

Da análise feita, percebe-se que os professores da escola Mpunzi Nzau são referidos em várias unidades de análise, sendo: "são unidos e não faltam de problemas"; "amigos, boas maneiras, mas todos não são iguais"; "nem todos temos aquela responsabilidade (pontualidade e dedicação)"; "são conflituosos"; "capacidade de querer desprezar", "neutralizar bagagem que vem com os alunos".

Tal como se acaba de constatar, os professores de Mpunzi Nzau se revelam em duas partes: a positiva e a negativa, sendo a positiva unidade entre eles, amizade no seu seio; e a negativa: promovedores de conflitos, irresponsabilidade no cumprimento da hora e déficit de dedicação, desprezam alunos e consideram-nos de tábua rasa ao ponto de se colocarem no centro das atenções.

\section{Considerações finais}

Este trabalho foi realizado na escola do Ensino Primário Mpunzi Nzau, em Cabinda, com professores que trabalham com a 6a classe. A pesquisa baseou-se na percepção do conceito professor por alguns professores que fizeram parte da nossa pesquisa. Os objetivos ligados ao tema foram alcançados, pois conseguimos trazer abordagem teórico-metodológica do conceito "professor" por meio de consultas bibliográficas e ouvimos, por meio de entrevistas, quatro professores da escola do Ensino Primário Mpunzi Nzau, em Cabinda, Angola, como eles percebem o conceito. 
A revisão da literatura conduziu à compreensão do conceito professor nas suas várias dimensões (psicológica, socioafetivas, profissional e social que são resumidas em humana, político-social e técnica), assim como tipologias de professores, requisitos necessários para ser professor, à luz dos autores consultados.

Os sujeitos entrevistados entendem e caracterizam o conceito professor em duas visões, a geral e a específica, para aqueles professores da escola em causa. Apontam indicadores indispensáveis na percepção do conceito professor: ser bom dirigente (ter competência para dirigir os seus alunos), orientador, condutor, um bom modelo para os seus alunos, capaz de relacionar-se com os colegas, ser bem apresentado e manter sempre uma boa imagem. Mas reconheceram que, no seio do coletivo, não faltam aqueles que se comportam mal e comprometem o bom ambiente laboral estabelecido, destacando desse modo dois polos: o polo positivo, caracterizado por unidade entre eles, amizade no seu seio, e o polo negativo, que se identifica com a promoção de conflitos, irresponsabilidade no cumprimento da hora e déficit de dedicação, desprezo aos alunos e consideram-nos de tábua rasa a ponto de eles mesmos se colocarem no centro das atenções, ao invés de serem os alunos.

No sentido geral, concluiu-se que o corpo de professores pesquisados daquela escola mostra questões que requerem intervenção quanto ao modo de atuação. Apesar de a maioria ter se formado em escolas vocacionadas à formação de professores, nem todos colocam em prática aquilo que aprenderam como alicerce para a sua profissão.

Dado os resultados deste estudo, surge a necessidade de dar continuidade a esta pesquisa em outras escolas do ensino primário, para se identificarem quais os reais problemas que afetam o coletivo de alunos e professores. Explorar ao máximo como os alunos de menor idade convivem com os desprezos vindos de seus professores e quais políticas as direções escolares traçam para se reduzir ou acabar com o problema. Por isso, a pesquisa sugere que os docentes coloquem em prática os conhecimentos adquiridos ao longo da formação para evitar controvérsias entre o tipo de professor ideal e a prática no exercício da profissão. Por um lado, e por outro, considerando que este estudo tem um potencial significativo para repensar a prática docente angolana, que se implemente a formação continuada ao longo da vida para atualizar as práticas pedagógicas e as concepções da educação no exercício da profissão.

\section{Referências}

ANGOLA. Ministério de Educação. Lei de Bases do Sistema Educativo n. 17/16 de 7 de outubro. Luanda, 2016. 
ANGOLA. Ministério de Educação. Lei de Base do Sistema Educativo 13/01 de 7 de outubro. Luanda, 2001.

ARENDS, Richard. Aprender a ensinar. Lisboa: Mcgraw-Hill, 2008.

CABRAL, Álvaro; NICK, Eva. Dicionário técnico de Psicologia. 13. ed. São Paulo: Cultrix, 2007.

CANDAU, Vera Maria et al. Tecendo a cidadania: oficinas pedagógicas de direitos humanos. 1. ed. Petrópolis, RJ: Vozes, 1995.

CANDAU, Vera Maria et al. Tecendo a cidadania: oficinas pedagógicas de direitos humanos. 2. ed. Petrópolis, RJ: Vozes, 1996.

DELORS, Jaques (coord). Educação: um tesouro a descobrir. Relatório para a UNESCO da Comissão Internacional sobre educação para o séc. XXI. Tradução de José Carlos Eufrázio. São Paulo: Cortez Editora. Brasília: Unesco, 1998.

FORMOSINHO, João. Formação de professores: aprendizagem profissional e ação docente. 1. ed. Lisboa: Porto Editora, 2009.

FREIRE, Paulo. Pedagogia da autonomia: saberes necessários à prática educativa. São Paulo: Paz e Terra, 1996.

FUMBA, Isabel Francisco Filipe. A importância da implementação do programa de aceleração escolar no processo de ensino e aprendizagem na escola primária Mpunzi Nzau, módulo 3, turma A, no ano 2013. Trabalho de Conclusão de Curso (Licenciatura em Ciências da Educação - Pedagogia - Gestão e Inspeção), Instituto Superior de Ciências da Educação, Cabinda, 2013.

GOMES, Romeu. Análise e interpretação de dados de pesquisa qualitativa. In: MINAYO, Maria Cecília de Sousa (coord.). Pesquisa social: teoria, método e criatividade. 13. ed. Petrópolis. RJ: Vozes, 2012.

LIBÂNEO, José Carlos. Pedagogia e modernidade: presente e futuro da escola. In: Seminário Nacional Infância, Escola, Modernidade, Universidade Federal do Paraná, 1994.

MENA, Maria. A influência da formação didáctico-pedagógica dos professores na aprendizagem dos alunos da 4a classe na Escola Comandante Gika, Cabinda. Trabalho Final do Curso de Licenciatura em Ciências da Educação, opção Pedagogia. Instituto Superior de Ciências da Educação, Cabinda, 2006.

PETERSON, Pedro Domingos. O professor do ensino básico: perfil e formação. Lisboa: Instituto Piaget, 2003.

RAMOS, Simão Puati Lando. Estrutura organizacional do sistema educativo angolano. In: Políticas de gestão de instituições educativas em Angola. 1. ed. Salvador, BA: Mestria Edições, 2019.

SAMBO, Domingos Sebastião Luemba. Precisamos sair dessa!: reflexões sobre a adolescência em Angola. 1. ed. Salvador, BA: Mestria Edições, 2018.

VASCONCELOS, Maria Lúcia Marcondes Carvalho. A formação do professor de terceiro grau. São Paulo: Pioneira, 1999. 